\section{MICROVASCULAR DYSFUNCTION AFTER MYOCARDIAL ISCHEMIA}

Endothelium-mediated relaxation and smooth muscle function in large coronary arteries are resistant to prolonged global ischemia. We used a small-vessel myograph to test the hypothesis that small intramyocardial artery endothelium and smooth muscle function have greater sensitivity to ischemic injury than large artery endothelium and smooth muscle. Normothermic global ischemia was induced in 15 porcine hearts. Intramyocardial arterial ring segments were assessed at $0,30,60,90$, and 120 minutes of ischemia in vitro with a small-vessel myograph. Potassium determined smooth muscle contraction, bradykinin endothelium-mediated relaxation, and sodium nitroprusside direct smooth muscle relaxation. Endotheliummediated relaxation after 30 minutes of ischemia was similar to control (56\% versus $66 \%$ ) but was impaired at 60,90 , and 120 minutes of ischemia $(32 \%, 11 \%$, and $6 \%)$. Smooth muscle contraction was unchanged at 30 and 60 minutes compared with control ( 56 and 53 versus $63 \mathrm{~mm} \mathrm{Hg}$ ) but was significantly decreased at 90 and 120 minutes (33 and $13 \mathrm{~mm} \mathrm{Hg}$ ). Direct smooth muscle relaxation was significantly decreased at 120 minutes of ischemia compared with control (58\% versus $95 \%$ ). In a previous study, epicardial coronary artery endothelium-mediated smooth muscle vasodilation and direct smooth muscle vasodilation were preserved until 160 minutes of ischemia. After 160 minutes of ischemia, endothelium-mediated relaxation was lost and only direct smooth muscle vasodilation was preserved. In contrast to vasodilation, vasoconstriction was significantly reduced at 140 minutes of ischemia. These data indicate a greater and earlier adverse effect of ischemia on intramyocardial arterial endothelium-mediated relaxation than smooth muscle contraction or relaxation. These data support the hypothesis that there is an early functional endothelial cell injury associated with global ischemia. Relaxation that is endothelium-dependant in intramyocardial arteries is more sensitive to ischemic injury than in epicardial arteries. Unique to this study was the evaluation of small intramyocardial arteries $(281 \pm 29 \mu \mathrm{m})$ that are the primary sites of coronary vascular resistance. Microvascular endothelial dysfunction after ischemia, therefore, may contribute to the "no-reflow phenomenon" seen during reperfusion injury. (J Thorac Cardiovasc Surg 1995;109:892-8)

Rebecca J. Dignan, MD, Margit Kadletz, MD, Cornelius M. Dyke, MD, Harry A. Lutz, MD, Thomas Yeh, Jr., MD, and Andrew S. Wechsler, MD, Richmond, Va.
En fusio ndothelial cell injury during ischemia and reperfusion has been implicated in the generation of oxygen-derived free radicals, platelet aggregation, and thrombosis and may be a mediator of myocardial reperfusion injury. Endothelial cells also pro-

From the Medical College of Virginia, Virginia Commonwealth University, Richmond, Va.

Read at the Twentieth Annual Meeting of The Western Thoracic Surgical Association, Olympic Valley, Calif., June 22-25, 1994.

Address for reprints: Rebecca J. Dignan, MD, MCV Station, Box 645, Medical College of Virginia, Richmond, VA 23298.

Copyright (C) 1995 by Mosby-Year Book, Inc.

$0022-5223 / 95 \$ 3.00+0 \quad \mathbf{1 2 / 6 / 6 3 1 8 6}$ duce neutrophil chemoattractants when subjected to hypoxia $^{1}$ and may be the target of leukocytes activated during ischemia. ${ }^{2}$

In a previous study, ${ }^{3}$ vasoconstriction and vasodilation of epicardial coronary arteries were preserved after an ischemic period associated with ischemic contracture of the myocardium. Technical considerations have limited in vitro examination of vasomotor function of intramyocardial arteries. In this report, we used a small-vessel myograph to test the hypothesis that small intramyocardial arteries are more sensitive to ischemic injury than large epicardial arteries. We also tested the hypothesis that intramyocardial arterial endothelium is more sensi- 
tive to ischemic injury than smooth muscle. Almost all other studies have evaluated the effects of combined ischemia and reperfusion. The purpose of this study was to define the effect of ischemia alone and eliminate the effect of reperfusion.

Vasorelaxation mediated by pharmacologically stimulated release of endothelium-derived relaxing factor was used as a biologic assay of endothelial cell function after global myocardial ischemic injury. Smooth muscle contractile and relaxant function was also tested by direct chemical stimulation.

\section{Methods}

Ten swine, weighing 25 to $35 \mathrm{~kg}$, were sedated with intramuscular acepromazine $(1.1 \mathrm{mg} / \mathrm{kg})$ and ketamine $(22 \mathrm{mg} / \mathrm{kg})$ and anesthetized with pentobarbital $(30 \mathrm{mg} /$ $\mathrm{kg})$. After intubation and heparinization $(30 \mathrm{U} / \mathrm{kg})$, rapid cardiectomy was performed. All protocols met the National Institutes of Health guidelines for the care and use of laboratory animals and were approved by the Institutional Animal Care and Use Committee of the Medical College of Virginia/Virginia Commonwealth University.

A portion of the myocardium containing the distal left anterior descending artery or distal circumflex artery and its intramyocardial branches was harvested in approximately 30 seconds to serve as preischemic control. The tissue was placed in $12^{\circ} \mathrm{C}$ phosphate-buffered saline solution for dissection and gassed with $95 \%$ oxygen and $5 \%$ carbon dioxide. The solution had the following composition (in millimoles per liter): $\mathrm{NaCl} 119, \mathrm{KCl} 4.6, \mathrm{CaCl}_{2} 2.5$, $\mathrm{MgSO}_{4} 1.17, \mathrm{NaHCO}_{3} 25, \mathrm{KH}_{2} \mathrm{PO}_{4} 1.17$, ethylenediaminetetraacetic acid 0.027 , and glucose 11 . Intramyocardial coronary artery ring segments (internal diameter 200 to $500 \mu \mathrm{m})$ were dissected free of surrounding tissue, cannulated with two stainless steel wires (inner diameter 40 $\mu \mathrm{m}$ ), and suspended on a small-vessel myograph (University of Aarhus, Aarhus, Denmark). One wire was attached to a force transducer (Dristler-Morse Corp., Bellevue, Wash.) and one wire to the micrometer (Mitutoyo, Tokyo, Japan). Ring segments were allowed to relax in the organ bath in oxygenated (95\% oxygen, 5\% carbon dioxide), normothermic, buffered saline solution for 60 minutes. They were incubated with indomethacin $10 \mu \mathrm{mol} / \mathrm{L}$ to prevent prostacyclin-mediated relaxation.

The remaining myocardial tissue was sealed in a small amount of phosphate-buffered saline solution to prevent desiccation and maintained at $37^{\circ} \mathrm{C}$ to simulate global normothermic ischemia. Intramyocardial branches from myocardium containing the distal left anterior descending or circumflex distal coronary artery were harvested and ring segments were prepared from the ischemic heart every 30 minutes in the same manner as the control tissue. All arterial segments were free of clotted blood.

Normalization of arterial diameters. A wide range of diameters was observed in the arteries obtained (200 to $500 \mu \mathrm{m}$ ). Therefore, a normalization procedure, previously described in detail,${ }^{3,4}$ was performed to standardize baseline resting length at which subsequent tension measurements were obtained. A passive length-tension curve was obtained for each arterial ring segment by progressively separating the wires holding the ring segment and recording the force on a linear recorder (Thomas Scientific, Swedesboro, N.J.). Measured force was converted to tension, length to circumference, and the relationship was plotted. A second plot solved the Laplace formula relating pressure to tension by assuming a constant pressure of $100 \mathrm{~mm} \mathrm{Hg}$ and calculating the tension at each internal circumference. The intersection of these two lines determined the internal circumference that ring segments would have at a transmural pressure of $100 \mathrm{~mm} \mathrm{Hg}$ and is called $\mathrm{L}_{100}$. The internal circumference of every ring segment was then set at $90 \%$ of $\mathrm{L}_{100}$, termed $\mathrm{L}_{90}$. The isometric force at this setting is the "passive" or "resting" force in the absence of constrictor tone. This method of determining resting force has been shown to allow maximum tension development while standardizing resting tension independent from arterial diameter. ${ }^{5}$

Arterial function. Arterial segments were allowed to equilibrate for 15 to 20 minutes at $\mathrm{L}_{90}$ before administration of vasoconstrictors (Fig. 1, $A$ and $B$ ). Ring segments were contracted with a $125 \mathrm{mmol} / \mathrm{L}$ solution of potassium chloride. The maximum pressure change after potassium $\left(\mathrm{dP}_{\mathrm{KCl}}\right)$ was recorded. Ring segments were rinsed and allowed to equilbrate after contraction to potassium. Potassium chloride, $45 \mathrm{mmol} / \mathrm{L}$, was used to contract the ring segment before relaxation. This concentration of potassium normally produced a contraction equal to $60 \%$ to $80 \%$ of the maximum potassium contraction. If adequate contraction $(60 \%$ to $80 \%)$ did not result, a 90 $\mathrm{mmol} / \mathrm{L}$ dose of potassium was administered. To test the endothelial component of relaxation, we repeatedly administered bradykinin in increasing concentrations from $10^{-8}$ to $10^{-5} \mathrm{~mol} / \mathrm{L}$ until maximum ring segment relaxation was achieved. When no additional relaxation was attained with bradykinin, sodium nitroprusside $10^{-4}$ $\mathrm{mol} / \mathrm{L}$ was added to define the maximum smooth muscle relaxation of each artery. This concentration of nitroprusside has been shown to maximize arterial relaxation with or without prior bradykinin administration by its direct action on arterial smooth muscle. ${ }^{3}$

Three measurements were used to quantify coronary smooth muscle function for each arterial ring segment studied: (1) the maximum pressure change in response to a $125 \mathrm{mmol} / \mathrm{L}$ dose of potassium $\left(\mathrm{dP}_{\mathrm{KCl}}\right),(2)$ the pressure change in response to a $45 \mathrm{mmol} / \mathrm{L}$ dose of potassium, and (3) the maximum smooth muscle relaxation defined as the sum of bradykinin- and nitroprusside-induced relaxation and reported as the percentage of $\mathrm{dP}_{\mathrm{KCl}}$. Endotheliummediated relaxation was defined for each arterial segment as the bradykinin-induced relaxation and reported as the percent of maximum total smooth muscle relaxation (Fig. $1, A$ and $B$ ). The ratio of bradykinin-induced relaxation to total relaxation was calculated to separate endothelial dysfunction from potentially impaired smooth muscle function. Total relaxation to sodium nitroprusside and bradykinin was calculated as a percent of contraction to determine the effect of ischemia on smooth muscle relaxation as a function of contraction.

Data analysis. All tension measurements were converted to pressure by means of the LaPlace relationship $(P=2 \pi T / L)$. Data in each group were tabulated and are 


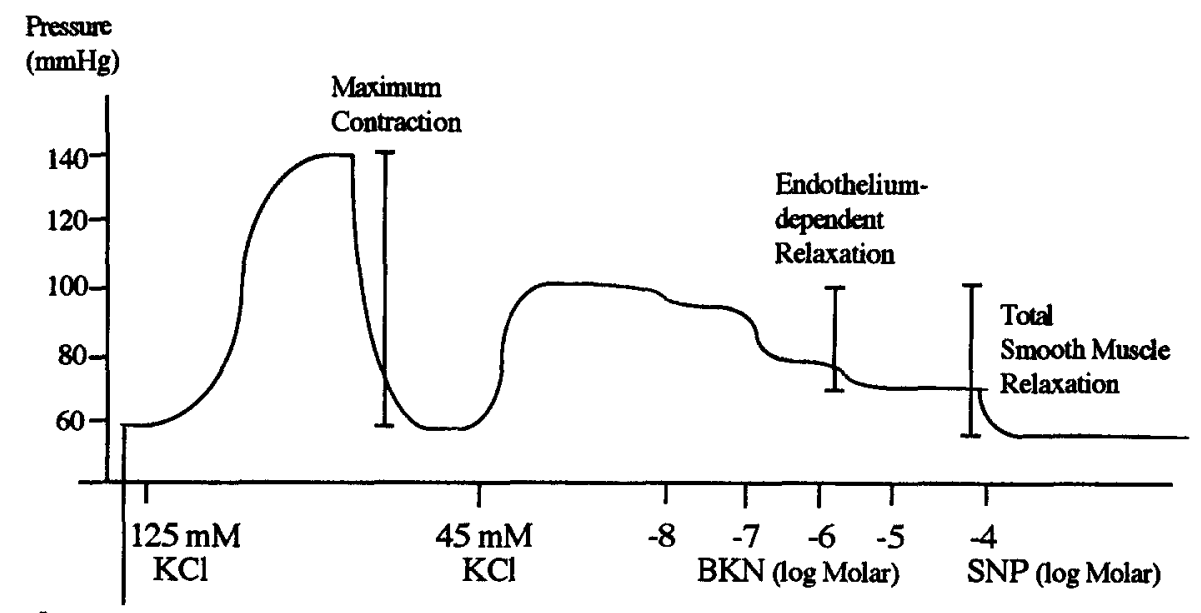

A $\mathrm{L} 90$

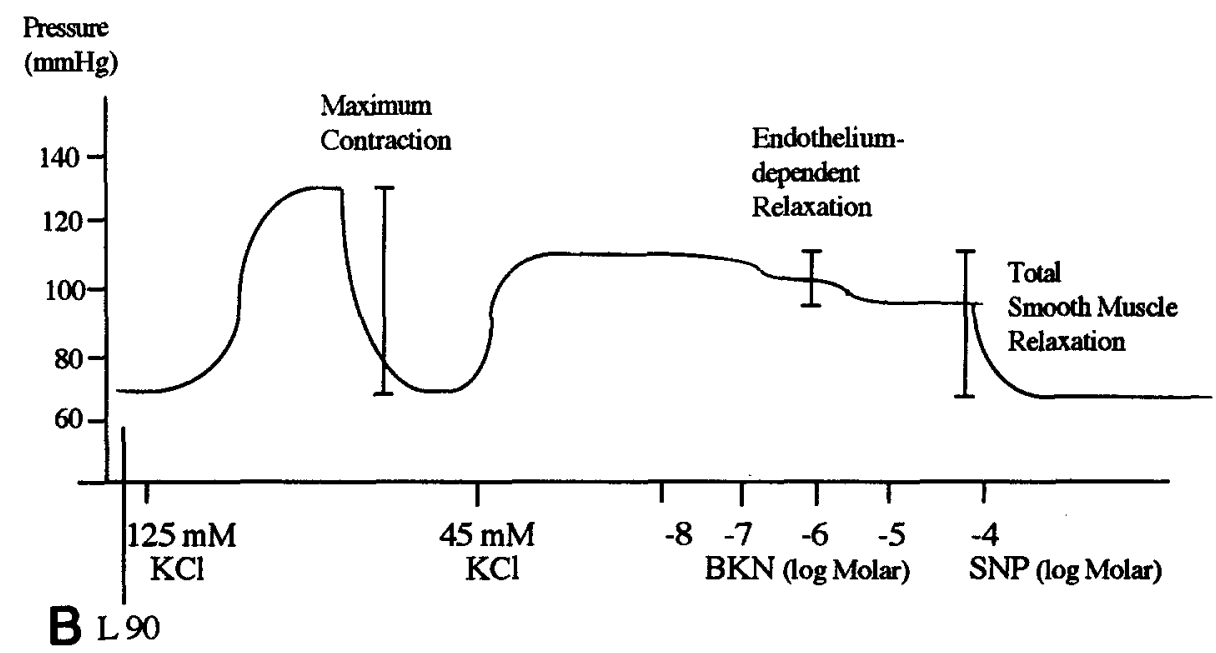

Fig. 1. Control (diameter $220 \mu \mathrm{m}$ ) and ischemic (diameter $360 \mu \mathrm{m}$ ) ring segment reactivity: raw data plots from preischemic control (A) and ischemic (60 minutes) intramyocardial arteries (B). Decline in percent of bradykinin-induced relaxation is demonstrated in the ring segment subject to 60 minutes of ischemia despite equal total relaxation. $B K N$, Bradykinin; $S N P$, sodium nitroprusside.

presented as mean \pm standard error of the mean. Means were compared between each group by analysis of variance, the unpaired $t$ test, and rank order analysis to determine significant differences between groups. Values were considered to be statistically significant when the $p$ value was less than 0.05 .

\section{Results}

Fig. $1, A$ and $B$ depicts raw data plots from a preischemic control ( $A, 0$ minutes) and an ischemic $(B, 60$ minutes) intramyocardial arterial ring segment. In the control artery, resting pressure was 59 $\mathrm{mm} \mathrm{Hg}\left(\mathrm{L}_{90}=220 \mu \mathrm{m}\right)$. Potassium chloride $(125$ $\mathrm{mmol} / \mathrm{L})$ produced maximum contraction $\left(\mathrm{dP}_{\mathrm{KCl}}, 79\right.$ $\mathrm{mm} \mathrm{Hg}$ ) and a $45 \mathrm{mmol} / \mathrm{L}$ dose of potassium produced $64 \%$ of maximum contraction ( $\mathrm{dP}_{\mathrm{KCl}}, 46$ $\mathrm{mm} \mathrm{Hg).} \mathrm{Relaxation} \mathrm{to} \mathrm{bradykinin} \mathrm{was} \mathrm{strong} \mathrm{(31}$ $\mathrm{mm} \mathrm{Hg}, 67 \%$ of total smooth muscle relaxation) and relaxation to sodium nitroprusside was relatively weaker $(17 \mathrm{~mm} \mathrm{Hg}$ ) because the artery relaxed significantly with bradykinin. Total smooth muscle relaxation in the control ring segment was $46 \mathrm{~mm}$ $\mathrm{Hg}$ (101\% of contraction).

In the ischemic artery (60 minutes), resting pressure was $69 \mathrm{~mm} \mathrm{Hg}\left(\mathrm{L}_{90}=360 \mu \mathrm{m}\right)$. Contraction to 


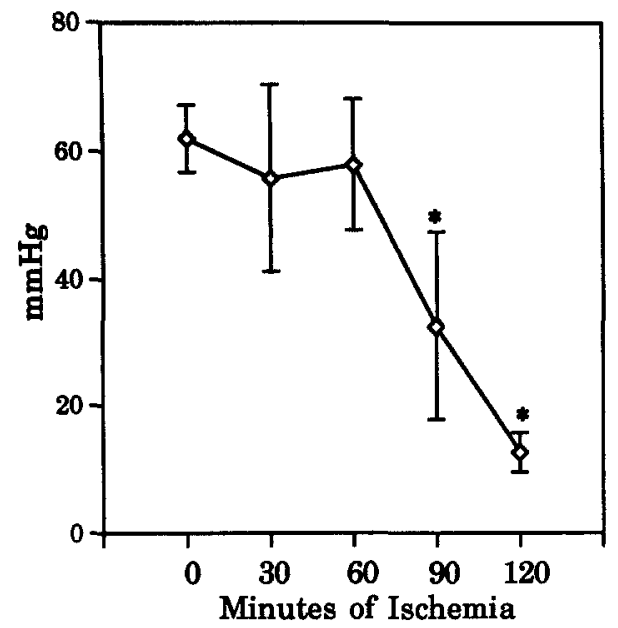

Fig. 2. Smooth muscle contraction to potassium chloride, $125 \mathrm{mmol} / \mathrm{L}$.

potassium was strong $(125 \mathrm{mmol} / \mathrm{L}, 60 \mathrm{~mm} \mathrm{Hg} ; 45$ $\mathrm{mmol} / \mathrm{L}, 44 \mathrm{~mm} \mathrm{Hg}$ ). There was diminished relaxation to bradykinin $(18 \mathrm{~mm} \mathrm{Hg} ; 40 \%$ of total smooth muscle relaxation) and proportionately greater direct smooth muscle relaxation mediated by sodium nitroprusside $(27 \mathrm{~mm} \mathrm{Hg})$. Total smooth muscle relaxation was $45 \mathrm{~mm} \mathrm{Hg} \mathrm{(103 \%} \mathrm{of} \mathrm{contraction).}$

A decline in the percent of bradykinin-induced relaxation is demonstrated in the artery subject to 60 minutes of ischemia ( $45 \%$ versus $67 \%$ in the control ring segment) despite equal total relaxation $(46 \mathrm{~mm}$ $\mathrm{Hg}$ and $44 \mathrm{~mm} \mathrm{Hg}$ ). This pattern of response is interpreted as a diminished response of the endothelium to bradykinin in an artery with equal smooth muscle contractile and relaxant capacity.

Fig. 1 demonstrates the higher resting pressure required in larger ring segments. The control ring segment was $220 \mu \mathrm{m}$ and had a resting pressure of 59 $\mathrm{mm} \mathrm{Hg}$. The ischemic ring segment had an internal diameter of $360 \mu \mathrm{m}$ and a resting pressure of $69 \mathrm{~mm}$ $\mathrm{Hg}$.

Arterial smooth muscle function. The graph in Fig. 2 shows the decline in average developed arterial pressure to a $125 \mathrm{mmol} / \mathrm{L}$ dose of potassium with increased ischemic time. Pressure is significantly diminished from $63 \mathrm{~mm} \mathrm{Hg}$ (control) to 33 and $13 \mathrm{~mm} \mathrm{Hg}(p<0.05)$ after 90 and 120 minutes of ischemia. Fig. 3 shows that the average pressure of contraction to a $45 \mathrm{mmol} / \mathrm{L}$ dose of potassium is not significantly decreased until 120 minutes compared with control arteries (from $32 \mathrm{~mm} \mathrm{Hg}$ to $6 \mathrm{~mm}$ $\mathrm{Hg} ; p<0.05$ ). This represents decreasing smooth muscle function. Fig. 4 illustrates that total relax-

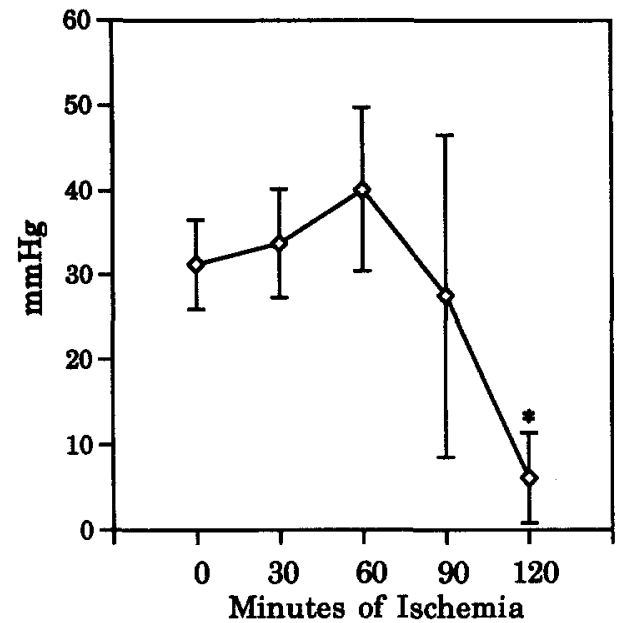

Fig. 3. Smooth muscle contraction to potassium chloride, $45 \mathrm{mmol} / \mathrm{L}$.

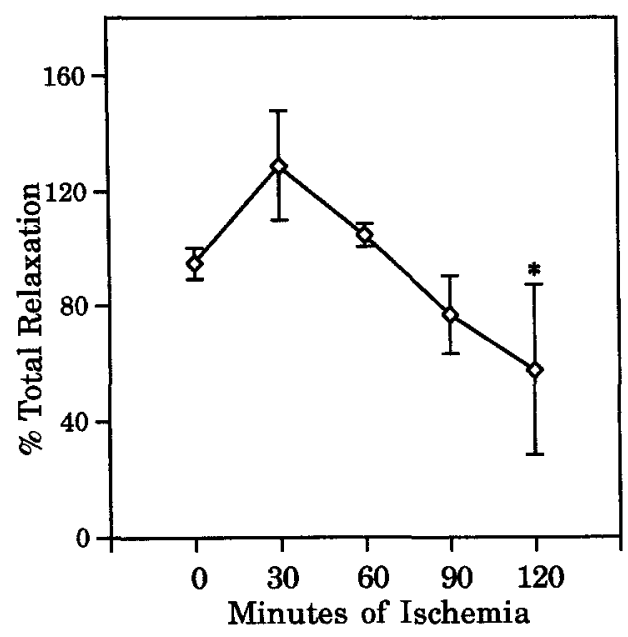

Fig. 4. Total smooth muscle relaxation to bradykinin plus sodium nitroprusside.

ation to combined bradykinin and sodium nitroprusside (as a percent of contraction induced by a 45 $\mathrm{mmol} / \mathrm{L}$ dose of potassium) was significantly decreased after 120 minutes of ischemia, indicating that smooth muscle relaxation as a percent of contraction is diminished by ischemia.

Arterial endothelial function. Fig. 5 represents coronary artery bradykinin-induced relaxation or endothelial function. The percent of bradykinininduced relaxation to total bradykinin plus sodium nitroprusside-mediated relaxation decreased significantly after 60,90 , and 120 minutes of ischemia. This represents a decrease in endothelial function separate from a decrease in smooth muscle function. 


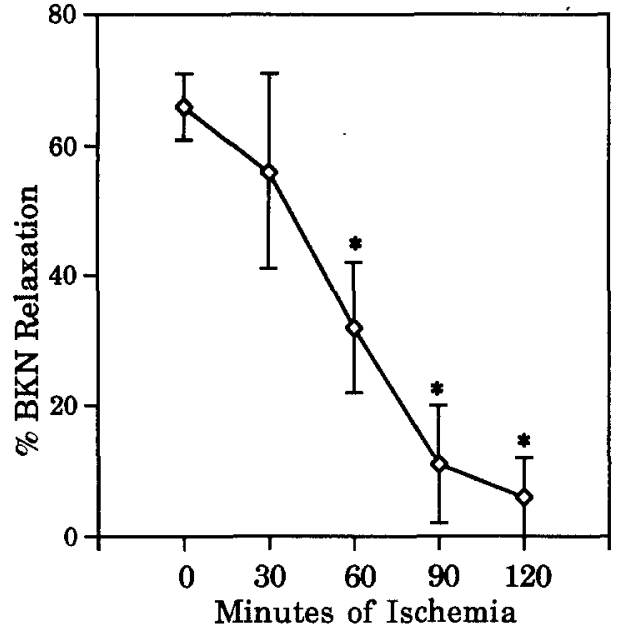

Fig. 5. Coronary artery bradykinin-induced relaxation; endothelium-mediated smooth muscle function. $B K N$, Bradykinin.

Calculation of bradykinin-induced relaxation relative to total relaxation rather than as an absolute value eliminates influence of diminished ischemic smooth muscle contraction on the results of endothelium-mediated relaxation.

\section{Comments}

This study demonstrates impaired vasodilator reactivity of coronary microarteries after ischemia. The sensitivity of intramyocardial arteries to ischemia was greater than that of epicardial arteries. The effect of ischemia on vascular smooth muscle contraction was similar to that in large arteries. ${ }^{3}$ These data also indicate a greater and earlier adverse effect of ischemia on endothelium-mediated relaxation than on smooth muscle contraction or relaxation. These data support the hypothesis that there is an early functional endothelial cell injury associated with global ischemia.

Previous studies ${ }^{3}$ on large epicardial coronary arteries showed preservation of both arterial endothelium-mediated smooth muscle vasodilation and direct smooth muscle vasodilation until 160 minutes of ischemia. After 160 minutes of ischemia, endothelium-mediated relaxation was lost and only direct smooth muscle vasodilation was preserved. In contrast to vasodilation, vasoconstriction was significantly reduced after 120 minutes of ischemia. In small intramyocardial arteries, however, endothelium-mediated relaxation was impaired at 60 minutes, smooth muscle contraction at 90 and 120 minutes, and smooth muscle relaxation at 120 minutes of ischemia.

Intramyocardial arteries seem histologically to be more susceptible to ischemia and reperfusion injury $^{6-8}$ than large epicardial arteries. Functional assessment by the release of endothelium-derived relaxing factor may be more sensitive than histologic observations alone. Prior studies indicate that small coronary artery funtion may also be more susceptible to ischemia and reperfusion injury than large artery function. ${ }^{9,10}$ In vivo studies have shown that coronary artery vasodilator reserve mediated by endothelium and smooth muscle is inhibited by ischemia and reperfusion. ${ }^{11}$ Small intramyocardial arteries have also been shown to be more susceptible than large arteries to injury by activated neutrophils. $^{12}$

Injury to small coronary artery endothelium and smooth muscle in the setting of hemorrhagic shock was recently reported. ${ }^{13}$ Diminished smooth muscle and endothelium-mediated relaxation of coronary arteries contribute to decreased vasodilator reserve and the subendocardial injury reported in hemorrhagic shock.

The cause of the difference in small and large artery susceptibility to ischemia and other injury can only be speculated. Coronary autoregulatory capacity varies transmurally in the heart. The subendocardium demonstrates lower autoregulatory capacity, therefore enhancing its susceptibility to necrosis during hemorrhagic shock. ${ }^{14,15}$ Several theories for this transmural variation in autoregulatory capacity have been postulated. The greater susceptibility of endothelium-mediated relaxation of small coronary arteries to ischemic injury ${ }^{9}$ than large coronary arteries may contribute to the lower autoregulatory capacity of intramyocardial arteries reported in hemorrhagic shock.

Coronary artery dysfunction after ischemia, however, may be caused by events operative at the level of the prearteriolar small artery endothelium. Unique to this study was the evaluation of intramyocardial small arteries $(281 \pm 29 \mu \mathrm{m})$ that are the primary sites of coronary vascular resistance. These data support the hypothesis that there is an early functional endothelial cell injury associated with global ischemia. Intramyocardial arterial endothelial dysfunction after ischemia may contribute to diminished coronary autoregulation and the "noreflow phenomenon" seen during reperfusion. Because these studies were performed ex vivo, reperfusion injury was not evaluated. The additional 
adverse sequelae of reperfusion require investigation.

\section{REFERENCES}

1. Farber HW, Center DM, Rounds S. Effect of ambient oxygen on cultured endothelial cells from different vascular beds. Am J Physiol 1987;253:H878-83.

2. Harlan JM. Neutrophil-mediated vascular injury. Acta Med Scand (Suppl) 1987;715:123-9.

3. Dignan RJ, Dyke CM, Abd-Elfattah A, et al. Coronary artery endothelial and smooth muscle dysfunction after global myocardial ischemia. Ann Thorac Surg 1992;53:311-7.

4. Mulvany MJ. Procedures for investigation of small vessels using small vessel myograph. Department of Pharmacology, Aarhus University, Aarhus, Denmark, 1988.

5. Mulvany MF, Halpern W. Contractile properties of small arterial resistance vessels in spontaneously hypertensive and normotensive rats. Circ Res 1977;41: 19-26.

6. Nevalainen TJ, Armiger LC, Gavin JB. Effects of ischaemia on vasculature. J Mol Cell Cardiol 1986;18: 7-10.

7. Kloner RA, Rude RE, Carlson N, Maroko PR, DeBoer LWV, Braunwald E. Ultrastructural evidence of microvascular damage and myocardial cell injury after coronary artery occlusion: Which comes first? Circulation 1980;62:945-52.

8. West PN, Connors JP, Clark RE, et al. Compromised microvascular integrity in ischemic myocardium. Lab Invest 1978;38:677-84

9. Quillen JE, Selke FW, Brooks LA, Harrison DG. Ischemia-reperfusion impairs endothelium-dependent relaxation of coronary microvessels but does not affect large arteries. Circulation 1990;82:586-94.

10. Selke FW, Quillen JE. Altered effects of vasopressin on the coronary circulation after ischemia. J THORAC Cardiovasc Surg 1992;104:357-63.

11. Sobey CG, Dusting GJ, Grossman HJ, Woodman OL. Impaired vasodilatation of epicardial coronary arteries and resistance vessels following myocardial ischemia and reperfusion in anesthetized dogs. Coron Artery Dis 1990;1:363-74.

12. Kadletz M, Dignan RJ, Loesser KE, Hess ML, Wechsler AS. Ischemia and activated neutrophils alter coronary microvascular but not epicardial coronary artery reactivity. J ThORAC CARDIOvASC SuRG 1994; 108:648-57.

13. Dignan RJ, Wechsler AS, DeMaria ES. Coronary vasomotor dysfunction following hemorrhagic shock. J Surg Res 1992;52:382-8.

14. Horton JW. Hemorrhagic shock impairs myocardial cell volume regulation and membrane integrity in dogs. Am J Physiol 1987;252;H1203-10.

15. Haunso S. Lower limits of blood flow autoregulation in different myocardial layers of the left ventricular free wall of dogs. Acta Physiol Scand 1981;112:349-50.

\section{Discussion}

Dr. Edward D. Verrier (Seattle, Wash.). It has been observed for many years that the subendocardium of the left ventricle is more vulnerable to ischemia than the subepicardium. The transmural distribution of coronary blood flow and the vulnerability of the subendocardium has been the subject of much investigation over the years. Much of that research has been done by young surgical investigators, many of whom are members of The Western Thoracic Surgical Association. For years the focus of coronary blood flow physiology and myocardial ischemia has centered on local metabolic, hemodynamic, or tissue factors across the wall. Investigators have postulated or documented different levels of adenosine triphosphate or adenosine across the wall, a higher myocardial oxygen consumption in the inner one third of the left ventricle, higher endomyocardial tissue pressures surrounding the microcirculation across the wall based on the vascular waterfall hypothesis of blood flow, or reversed blood flow into the epicardial capacitant vessels during systole and short subendocardial perfusion during diastole. Only recently have we focused on endothelial physiology and reperfusion as essential culprits in contributing to the temporary functional loss and ultimate necrosis of the left ventricle. The present authors have focused on endothelial biology by documenting a differential vascular reactivity across the left ventricular wall in both vasoconstrictor and vasodilatory responses after varying periods of ischemia. A sensitive small-vessel myograph was used to study arterial vessels measuring 200 to $500 \mu \mathrm{m}$ by measuring developed tension to the vasoconstrictive agonist potassium chloride, the endothelium-dependent vasodilator bradykinin, and the smooth muscle vasodilator sodium nitroprusside. Endothelium-dependent vasodilator responses were most vulnerable to the shortest period of ischemia but ultimately over 120 minutes of ischemia all responses became impaired. I believe the present study is well conceived and well executed, as we have come to know from Dr. Wechsler's laboratory.

I have a couple of questions for Dr. Dignan. In most other studies of microcirculatory arteriolar resistant vessels, investigators had focused on vessels of 90 to $190 \mu \mathrm{m}$. You chose vessels in the 200 to $500 \mu \mathrm{m}$ range with a mean of approximately $300 \mu \mathrm{m}$. Was this a technical limitation or do you believe such sized vessels are the appropriate critical focus?

Dr. Dignan. The critical focus for defining ischemic and perfusion injury to myocardial blood vessels is probably at the capillary level. Although this study tested vessels that are slightly larger than capillaries, 200 to $500 \mu \mathrm{m}$, it give a good indication of the events operative at the capillary level.

Dr. Verrier. Could you explain the difference in internal diameter and pressure at the end of your 60-minute group versus the control group? The internal diameter was almost twice the size of the group that was subjected to 60 minutes of ischemia and almost $11 \mathrm{~mm}$ greater in pres- 
sure. Is there a reason for that, and does that affect the results?

Dr. Dignan. The differences in diameter do not affect the results, as explained in the published article but not at the presentation at the Western Thoracic because of time constraints. The normalization procedure allows adjustment of the resting pressure for larger ring segments and the experimental group was not significantly different from control.

Dr. Verrier. Mechanistically, do you believe that the ultimate endothelial contribution to ischemia and reperfusion is due to these conceptually potentially transient phenomena of vascular reactivity versus the ultimate reperfusion response of bringing in neutrophils, up-regulation of adhesion molecules, or up-regulation of those factors that may contribute to coagulation at this subendocardial microcirculatory level?

Dr. Dignan. There appears to be significant warm ischemic injury to endothelium and the mechanism of vasorelaxation that is probably not transient. It may actually be the inciting event for the events that follow, such as reperfusion injury and other events that you mentioned, Dr. Verrier. We recently completed a study showing that interaction of neutrophils with endothelial cells already injured by ischemia is more injurious than reperfusion of endothelial cells that have not been injured by ischemia.

Dr. Verrier. The vascular endothelium has emerged as a prime mediator of reactivity, ischemic reperfusion, inflammation, and intimal proliferative processes. Your excellent paper further gives insight into these relationships.

\section{1-800-55-MOSBY}

This number links you to the full text of articles published in over 25,000 journals, including all Mosby journals. MOSBY Document Express $^{\mathrm{TM}}$, a rapid response information retrieval service, provides quick turnaround, 24-hour availability, and speedy delivery methods. For inquiries and pricing information, call our toll-free, 24-hour order line: 1-800-55-MOSBY; outside the United States: 415-259-5046; fax: 415-259-5019; E-mail: mosbyexp@class.org.

MOSBY Document Express ${ }^{T M}$ is offered in cooperation with Dynamic Information Corp. 